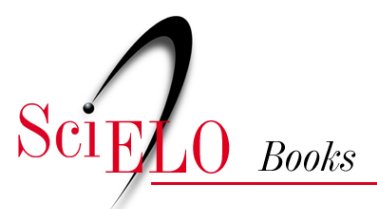

EDUFU

\title{
Dorothy Heathcote \\ mediação e intervenção na construção da narrativa teatral em grupo
}

\author{
Beatriz Cabral (Biange)
}

\section{SciELO Books / SciELO Livros / SciELO Libros}

CABRAL, B. Dorothy Heathcote: mediação e intervenção na construção da narrativa teatral em grupo. In: FLORENTINO, A., and TELLES, N., eds. Cartografias do ensino do teatro [online]. Uberlândia: EDUFU, 2008, pp. 37-48. ISBN 978-85-7078-518-3.

https://doi.org/10.7476/9788570785183.0005.

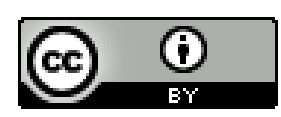

All the contents of this work, except where otherwise noted, is licensed under a Creative Commons Attribution 4.0 International license.

Todo o conteúdo deste trabalho, exceto quando houver ressalva, é publicado sob a licença Creative Commons Atribição $\underline{4.0}$.

Todo el contenido de esta obra, excepto donde se indique lo contrario, está bajo licencia de la licencia $\underline{\text { Creative Commons }}$ Reconocimento 4.0. 


\section{DOROTHY HEATHCOTE: MEDIAÇÃO E INTERVENÇÃO NA CONSTRUÇÃO DA NARRATIVA TEATRAL EM GRUPO}

Beatriz Cabral (Biange)

Este estudo focaliza as similaridades entre as abordagens de Dorothy Heathcote ${ }^{1}$, Augusto Boal e Bertolt Brecht, chamando atenção, particularmente, para o potencial da forma de "intervenção", usada por Heathcote para intensificar a dimensão crítica na prática usualmente fragmentada do teatro no contexto curricular. A partir destas similaridades é possível observar mais claramente o 'particular' do estilo da autora - a forma pela qual ela, continuamente, amplia e ressalta a qualidade da contribuição do aluno.

Heathcote promove experiências de drama a partir de materiais históricos: fatos, documentos, objetos, fragmentos de texto de autores diversos. Sua abordagem é totalmente oposta à representação. Caracteriza-se como intervenção. Como resultado, desenvolve uma narrativa coletiva similar a uma colagem, e os elementos desta colagem podem ser reorganizados novamente em qualquer direção e a partir de outra perspectiva. A intervenção se dá ao nível da estrutura e do questionamento - os significados são produzidos pelos participantes e por eles transformados; não há assim uma 'verdade' autoral estabelecida pelo professor. No drama, e em especial na abordagem de Heathcote, o material oferecido aos alunos (imagens ou textos) é desconstruído; torna-se uma pista para mediar as interações.

Tal como Boal e Brecht, Heathcote manifesta uma preocupação com a forma: confrontos espaciais, signos visuais de linguagem (cartões, posters, banners, rótulos, manchetes), atuação dialética através de uma troca de enquadramentos e papéis, foco no gesto (identidade a partir de um código de relações sociais).

Os três teatrólogos, na esfera da pedagogia, usam intencionalmente a lógica e a linguagem para trazer à tona as contradições dos personagens e sua história. Neste sentido, a dialética é sua piéce de rèsistance. Associar a dialética ao pós-modernismo pode parecer contraditório; entretanto, a dialética hoje é reconhecida como parte da natureza da comunicação humana. De acordo com Elizabeth Wright, "a dialética é

${ }^{1}$ Dorothy Heathcote é considerada a criadora do process drama, forma teatral inglesa, desenvolvida no contexto escolar, e equivalente ao Teatro-Educação brasileiro. 
o padrão de mudança de qualquer conceito ou significado que resulta da colocação da fonte de referência em um novo contexto de relevância, uma nova perspectiva intencional"'.

Os críticos de Brecht apontaram para o fato de que "o foco na forma reduz o elemento dialético das peças em tal grau que nada resta lá a não ser a dialética ${ }^{3 "}$. Porém, não apenas Brecht, mas também Boal e Heathcote, em diferentes culturas e através de métodos distintos, usam a forma para desafiar os códigos de representação aceitos e estabelecidos. É jogando com a forma que eles interrompem, congelam e marcam a ação, a fim de salientar as contradições da ordem social.

\section{Brecht e Boal na perspectiva do drama inglês}

Dois artigos são referenciais para se considerar a influência de Brecht e Boal na prática do teatro na escola nos países de língua inglesa: "Ways of seeing"4 e "Dra-

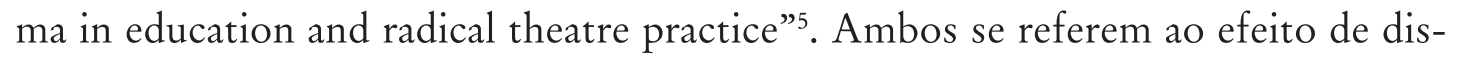
tanciamento e ao lugar do espectador na aula de drama.

O’Neill observou em 1989:

[...] a única experiência de platéia que os participantes deveriam ter durante uma aula de drama seria quando 'apresentações em pequenos grupos' ou improvisações 'polidas'fossem compartilhadas com o restante da turma, usualmente como conclusão de um trabalho. Esta é talvez o tipo de platéia menos útil para interpretar ou ser parte do processo. Tal platéia pode ser egoísta, crítica ou mesmo destrutiva em suas respostas $[\ldots]^{6}$.

Alternativamente, ela chama atenção para a dupla realidade de ser participante e espectador ao mesmo tempo, e lembra que Boal esclareceu a natureza desta dupla realidade, desenvolvendo um método onde os espectadores não só recebem idéias, mas também sobem ao palco e as praticam, criando uma dupla consciência, por ele denominada 'metaxis'.

Mas, se para Boal os espectadores são observadores ativos que supostamente intervém na ação como indivíduos, o 'espectador consciente’ de O’Neill implica um grupo com 'unicidade de resposta':

O contágio social opera para criar pressão em direção a uma conformidade do grupo, acordo e aceitação [...] o professor de drama pode controlar esta energia do grupo, ampliar seu efeito e forçar o acordo, especialmente nas etapas iniciais do trabalho, para estabelecer o contexto dramático'.

${ }^{2}$ WRIGHT, Elizabeth. Post-modern Brecht. Londres: Routledge, 1984. p. 14.

3 WRIGHT, 1984, p. 15.

${ }^{4}$ O’NEILL, Cecily. Ways of seeing: audience function in drama and theatre. 2D, n. 8, p. 17-29, 1989.

${ }^{5}$ LACEY, Stephan; WOOLLAND, Brian. Drama in education and radical theatre practice. New Theatre Quarterly, v. 8, p. 4-15, 1992.

6 O'NEILL, 1989.

7 O’NEILL, 1989. 
É possível atingir este estado mental através do 'professor-personagem' (teacher-in-role) e O'Neill comenta sobre a habilidade de Heathcote para tornar o grupo espectador de seu papel. Esta uniformidade de resposta é atingida, ela argumenta, quando a ambivalência de sentimentos é a resposta individual predominante. Esta ambivalência é algo que Heathcote explora de forma positiva, diz O’Neill, trabalhando papéis com potencial para provocar hostilidade (comandante militar, guardião de prisão, etc.), os quais unem o grupo contra ela e, conseqüentemente, reforçam e fortalecem os papéis dos alunos.

Além dessa unicidade de resposta ao professor-personagem, a ambivalência de operar em dois níveis ao mesmo tempo estimula os alunos a trabalhar, segundo Ken Robinson", "com um forte sentido de ser espectador de si mesmos e de suas próprias ações". É a partir desta combinação de participante e espectador que Gavin Bolton constrói a idéia de "percipiente", para designar o participante ativamente engajado naquilo que ele observa e responsável por criar a cena ou apresentação em primeira mão. De acordo com O'Neill, o "percipiente" resulta do entendimento de Bolton de que a luta dos professores para promover a reflexão dentro do processo dramático tem sido inimiga da forma, uma vez que seria necessário interromper a atividade para conseguir um tempo para reflexão. O conceito de percipiente introduz a idéia de que a observação é possível em ação, isto é, sem interromper o processo dramático.

Para O'Neill, o percipiente ou a mente de espectador (o estado mental de ser espectador) deve estar presente no fazer teatral, "pois, se sairmos completamente da ação para iniciar a reflexão, podemos descobrir que não há nada lá para ser refletido". Como um exemplo de "observar" enquanto um princípio estrutural no drama, a autora cita as estratégias de enquadramento de Heathcote, as quais estabelecem a observação e o julgamento a partir do início da atividade, através dos papéis escolhidos para os alunos (vide na frente).

\section{O relacionamento espectador-ator}

Para Lacey e Woolland ${ }^{10}$, "o Drama Educação não apenas se entrelaça com o teatro por caminhos marginais, mas é em si uma forma de prática teatral”. Eles ilustram seu argumento discorrendo sobre aspectos do modernismo pós-Brechtiano na Inglaterra, principalmente sobre a influência de Augusto Boal e Paulo Freire na prática do drama. Em vez de focalizar o percipiente, eles analisam a troca de funções durante a atividade - os participantes como platéia, uns dos outros.

Os autores enfatizam que para Brecht, a forma não é apenas o que é dado aos participantes para ser interpretado, mas é também o que deve ser negociado. A decorrência foi colocar o espectador no centro do debate e a criação da Lebrstuck ${ }^{11}$. As lehrstücke, segundo Lacy e Woolland, foram criadas, inicialmente, para uso com um

\footnotetext{
${ }_{8}^{8}$ ROBINSON, Ken. Exploring theatre and education. Londres: Heinemann, 1980. 185 p.

9 O'NEILL, 1989.

${ }^{10}$ LACEY; WOOLLAND, 1992.

${ }^{11}$ Brecht traduziu Lehrtuck como 'learning play' (peça de aprendizagem) em seu ensaio "Das deutsche Theatrer der Awanziger Jahre", Arquivo Bertolt Brecht 147/33-36. Referência de Reiner Steinweg em KOUDELA, Ingrid. Brecht: um jogo de aprendizagem. São Paulo: Perspectiva, 1991. p. 98.
} 
grupo de participantes sem a presença de um público além dos próprios atores. $\mathrm{O}$ objetivo era transformar a arte numa prática social através de um processo de observação e ação, trabalhar e re-trabalhar o texto, o qual estaria sempre aberto a mudanças.

Boal baseou seu método em Brecht e na pedagogia radical de Paulo Freire. Ambos focalizam o conceito de "práxis" e enfatizam que nós podemos compreender e transformar o mundo através da associação entre teoria e prática, isto é, através da reflexão e da ação. No âmbito da metodologia, esta perspectiva propõe um experimentar de alternativas baseadas na escolha do espectador, e abre espaço para tomadas de decisão, o que oferece meios de controle significativos ao observador-participante. Segundo Boal, o espectador "delega poder ao ator, que então age em seu lugar”. Lacey e Woolland exemplificam sua prática com esta atuação de expectativas através da descrição de uma aula onde os personagens não são apenas vistos ser construídos, são também propositalmente criados por espectadores ativos.

\section{O espectador de si mesmo (self-spectator)}

Os ensaios comentados acima se referem às influências de Brecht e Boal no Drama, mas suas abordagens ao papel do espectador no desenvolvimento do texto coletivo são bem distintas.

Em Ways of seeing, O’Neill ${ }^{12}$ enfatiza o espectador implícito como a contribuição mais útil para manter o envolvimento com o processo dramático e evitar a separação entre ação e reflexão. O conceito de "metaxis" é observado em sua dimensão temporal - como uma dupla consciência de pertencer a dois mundos ao mesmo tempo.

Para Lacey e Woolland, observar e atuar são atitudes distintas quanto às dimensões formais e temporais. Metaxis, para eles, significa a possibilidade do ator manter ambos os papéis, observador e ator, em diferentes momentos. Como observadores, eles são capazes de sugerir alternativas para aquilo que lhes foi apresentado.

Entretanto, as duas abordagens são mais similares do que parecem. A similaridade reside no fato de que não há platéia além do próprio grupo. Quando este se subdivide em pequenos grupos ou equipes, todos estão envolvidos no mesmo evento e suas alternativas respondem ao mesmo contexto de ficção.

Qual a origem pedagógica desta perspectiva metodológica?

A partir de 1930, Brecht passou a insistir em uma "regra básica" para diferenciar o jogo de aprendizagem da peça épica: "atuar para si próprio é o pressuposto para a realização do jogo de aprendizagem como um ato artístico ${ }^{13}$ ”. Segundo Walter Benjamin, "o jogo de aprendizagem figura como uma situação específica devido à sua pobreza de aparato, simplificando o relacionamento entre ator e espectador. Cada espectador é, ao mesmo tempo, um observador e um ator ${ }^{14 "}$. A influência de Brecht na prática do Drama se refere principalmente a este aspecto de sua teoria da aprendizagem: não sendo platéia das apresentações de outras pessoas, os participantes tornam-se espectadores de si mesmos ${ }^{15}$, de seus próprios argumentos e atitudes.

\footnotetext{
12 O’NEILL, 1989.

13 STEINWEG, Reiner. Das lebrstuck. Stuttgart: Metzler, 1972. p. 87.

14 BENJAMIN, Walter. Versuche über Brecht. Frankfurt: Sührkamp, 1981. p. 36.

15 Dorothy Heathcote cunhou a expressão "self-spectator" (auto-espectador) para identificar a situação aqui descrita como "espectador de si mesmo".
} 


\section{Implicações da influência de Brecht e Boal no Drama}

O trabalho didático de Brecht estava baseado não apenas em textos, mas em bons textos. As Lehrstücke contêm um teor desafiante (quanto à forma e ao assunto) e de grande dramaticidade, que chamam por diferentes atitudes e permitem desvelar vieses ideológicos.

Boal re-trabalhou os critérios de Brecht e introduziu novas convenções para aumentar o distanciamento entre o observador e o personagem, por exemplo, o "sistema coringa", através do qual os atores se alternam para representar a mesma personagem. Boal não usa texto, mas trabalha com um grupo de atores com habilidades para aceitar as sugestões da platéia e experimentá-las para checar possíveis alternativas para o problema ${ }^{16}$. Para traduzir estas experiências para o Drama, em sala de aula, sem um texto dramático ou atores que interpretem as contribuições dos espectadores, a ampliação do campo de referências e do conceitual dependerá do input do professor. Isto se refere tanto à qualidade da atuação do professor (pedagógica ou artística), quanto ao(s) texto(s) usado(s) para engajar os participantes com a construção verbal (falada, escrita ou cantada) e visual (física, espacial e cênica) do processo do Drama. Um procedimento que assegura ao professor a delimitação de um campo de atuação, onde poderá ampliar, gradualmente, a introdução de referências, problemas a serem resolvidos, e desafios (confrontos), sem perder a coerência interna da narrativa em construção, tem sido o uso de um texto como pré-texto.

O texto, como pré-texto, segundo Cecily O’Neill, “opera em diferentes momentos como uma espécie de 'forma-suporte' para os demais significados a serem explorados ${ }^{17}$ ". Como pano de fundo, o texto torna-se uma referência para alternativas de ações, e subsidia o professor na seleção e orientação dos jogos teatrais na identificação do contexto e na busca de coerência interna para a narrativa em processo.

A noção de pré-texto indica a necessidade de desconstruir o texto dramático a fim de adaptá-lo às condições e motivações do grupo, ou introduzir parâmetros artísticos de estrutura e linguagem a fim de transgredir os limites do cotidiano e do “já visto”. Trata-se de um procedimento metodológico que permite, por um lado, delimitar as interações dos participantes a partir do cruzamento de fragmentos do texto com histórias de vida, e, por outro lado, ampliar as formas de olhar e entender o texto e a cena através do jogo teatral. Entretanto, a re-construção do texto dramático ou a criação coletiva a partir de fragmentos do texto, exige a habilidade de um dramaturgista. No contexto escolar, esta constatação exige uma investigação metodológica contínua.

A preocupação com o que os alunos aprendem ao participar do Drama tem sido expressa e analisada por David Hornbrook, o qual sugere que devemos investigar métodos que possibilitem aos alunos seu desenvolvimento como leitores do Drama, como espectadores das histórias de outras pessoas, tornando-se assim "al-

\footnotetext{
$\overline{16}$ Não estou incluindo aqui o "teatro de imagens", por considerá-lo uma estratégia e não uma forma teatral que introduza elementos da linguagem cênica - estes podem ser trabalhados se o professor acrescentar outras estratégias de leitura ou construção da cena.

${ }_{17}$ O’NEILL, Cecily. Dram worlds: a framework for process drama. Londres: Heinemann, 1995. p. 22.
} 
fabetizados nas questões do palco ${ }^{18}$.

Em princípio, pode-se argumentar que "alfabetizar em teatro" depende mais da habilidade do professor para estruturar a atividade, selecionar as convenções apropriadas e apontar as múltiplas faces do texto teatral durante seu processo de criação do que da seleção de um texto, gênero ou tema.

$\mathrm{O}$ fato de que muitos professores se eximem de trabalhar com montagens no contexto escolar é tão verdade quanto aquele dos professores que costumam envolver os alunos com uma peça simplesmente pedindo que distribuam os personagens entre si, memorizem e apresentem o texto. Parâmetros curriculares, semana de planejamento e coordenação de área ajudam apenas em parte, se o professor não tiver habilidade, conhecimento específico e experiência para estruturar e seqüenciar o trabalho, de maneira a possibilitar que os alunos percebam e compreendam as regras e convenções teatrais durante o desenvolvimento do processo dramático enquanto as usam. É esta compreensão que irá permitir que eles se tornem leitores críticos tanto de espetáculos teatrais quanto de outros meios de comunicação. $\mathrm{O}$ importante aqui é que o drama, quer desenvolvido como construção coletiva com base na escolha temática dos alunos, quer a partir de um texto dramático, exige um considerável input do professor durante o processo de descoberta gradual do texto e de seus subtextos potenciais. Em ambos os casos, o papel do leitor e o espaço da leitura são fundamentais.

\section{Dorothy Heathcote - significação em processo}

Muito tem sido escrito a respeito da influência de Dorothy Heathcote sobre os professores de Drama e o alto grau de intervenção de seu modo de ensino. $\mathrm{O}$ argumento, aqui, é que este consiste em um método dialético, no qual a intervenção funciona como um quebra-cabeça que oscila constantemente entre os níveis metodológico e ideológico. No seu aspecto externo, a intervenção reside na esfera da metodologia - ao estruturar e seqüenciar o trabalho - cada tarefa proposta por Heathcote põe em cheque a criação anterior e traz à tona as implicações das atitudes tomadas pelos alunos na tarefa precedente. Quanto ao nível ideológico, a intervenção de Heathcote tem como foco o "leitor"19 - ela aceita todas as contribuições dos alunos e interage com eles através de desafios postos pelas tarefas que vai introduzindo a seguir. Pode-se dizer que ao selecionar as convenções e estratégias e em dar prosseguimento à narrativa, Heathcote administra a percepção dos participantes sobre a situação em pauta e, desta forma, intervém ideologicamente no processo.

Entretanto, embora ela determine o material de trabalho ${ }^{20}$, ao introduzi-lo e propor as tarefas para sua exploração, os alunos o lêem e o usam à vontade. Sua intervenção não é explícita; ocorre indiretamente, através de tarefas que tornam evidente as implicações das ações tomadas anteriormente. A cada novo

\footnotetext{
${ }_{18}$ HORNBROOK, David. Education in drama. Londres: Falmer Press, 1991. p. 6.

${ }_{19}$ O conceito de leitor, que nas recentes teorias de produção e recepção adquiriu um forte sentido de "produtor de significados", mantém aqui as noções de espectador e percipiente; e tem sido comumente usado para afirmar a autoria do aluno sobre o texto que está sendo produzido. ${ }^{20}$ Material de trabalho refere-se aqui a tudo o que o professor introduzir para iniciar o Drama ou durante seu processo - texto ou fragmentos de texto, objetos de cena, fotos e outros impressos, figurino, etc.
} 
episódio, Heathcote leva em consideração as decisões e ritmo dos alunos, tal como observados na etapa anterior - isto torna possível dizer que são os alunos que, em última instância, definem a seqüência e a estrutura do trabalho, e que sua abordagem dialética leva a um processo contínuo de ampliar e aperfeiçoar as formas de recepção dos participantes.

Trata-se assim de um método de trabalho onde o professor amplia e aperfeiçoa o conteúdo (o quê está sendo investigado cenicamente) através da forma (o como está sendo trabalhado).

A participação em processos de Drama coordenados por Heathcote, entre os anos de 1990 e $1994^{21}$, permitiu-me observar um padrão comum às diferentes experiências:

- o professor "lê" tanto o contexto quanto a atitude dos participantes, e questiona o conhecimento destes sobre o assunto a ser investigado através do Drama;

- o professor amplia e realça a contribuição do aluno, reformulando-a ou salien tando aspectos que possam representar boas oportunidades de aprendizagem;

- o professor pinça no Drama em andamento um problema com potencial dramático, introduz uma nova convenção e direciona o processo nesta direção;

- o professor desafia a leitura que os participantes fazem das circunstâncias que estão sendo exploradas, principalmente através da introdução de novas convenções que promovam uma troca entre expressões verbais e visuais;

- o ponto de vista ou perspectiva predominante no desenvolvimento de um episódio será o ponto de partida do próximo.

\section{O bom samaritano}

"Um homem caminhava de Jerusalém para Jericó quando caiu nas mãos de assaltantes. Os ladrões tiraram tudo o que ele tinha, bateram nele e o deixaram semimorto à beira da estrada. Aconteceu que um padre seguia pela mesma estrada; mas quando ele o viu, passou para a outra margem. Assim, também um Levita chegou ao local e quando o viu passou para o outro lado. Mas um samaritano que estava fazendo a mesma jornada, chegou até ele e ao vê-lo foi tomado pela piedade. Ele o levantou e fez uma bandagem em seus ferimentos, banhando-os com óleo e vinho. Então, ele o colocou em seu próprio animal e o levou consigo para uma estalagem, cuidando dele ao chegar. No dia seguinte, ele deu duas moedas de prata ao estalajadeiro e disse, 'cuide dele; se você gastar mais, eu lhe re-embolsarei em meu caminho de volta"'22.

Dorothy Heathcote, ao propor o uso de O bom samaritano como pré-texto em um seminário do curso de Mestrado em Drama Educação, na Politécnica de Birmingham em 1992, salientou a importância de o professor lembrar dois procedimentos básicos para se iniciar qualquer processo de drama:

1. achar o elemento de tensão em cada episódio, sempre lembrando que lidar

\footnotetext{
${ }^{21}$ Neste período, participei dos seguintes trabalhos: "Mary Morgan", "O bom samaritano", "Dr Knox", "Vivendo sob uma ditadura", "Channel Islands durante a ocupação nazista", "O projeto de pesquisa Oxfam", todos disponíveis em vídeo no Centro de Estudos em Drama na Educação, da University of Central England, em Birmingham.

${ }_{22}$ Lucas 10, 29-35
} 
com limitações evita que nos fixemos nas circunstâncias. Por exemplo, o homem não poderá evitar a viagem, mesmo sabendo ser ela perigosa;

2. a tarefa escolhida não deve ser negociada, pois o tipo de aprendizagem gerado relaciona-se com ela. Cabe ao professor determiná-la.

De acordo com Heathcote, o professor deve definir os elementos de tensão e tarefas para cada episódio a partir do enquadramento e perspectiva da cena. Com a parábola do samaritano, ela pretende levar os participantes a considerar a natureza de correr riscos, aqui decorrentes da ajuda a inimigos moribundos. Assim, seja qual for o enquadramento escolhido, o objetivo da escolha é se aproximar deste entendimento sobre a natureza dos riscos. Os diferentes enquadramentos vão determinar o relacionamento do grupo com a parábola e seu olhar sobre as situações propostas em cada episódio. Como ressalta Heathcote, em sua prática, se as crianças querem uma "batalha”, rememorá-la, compreendê-la e entender suas estratégias é de diferente ordem do que interpretá-la.

Perspectivas de Enquadramento - alternativas para O bom samaritano:

Agente: como argumento é proposto um programa de TV, onde um comerciante aleijado (juntamente com seu libertador) está relembrando o momento em que foi atacado. O programa dará a seu salvador uma medalha de bravura. O contexto requer uma imagem acurada e detalhada - repórteres, câmera, som, tribunal. A violência seria demonstrada e não interpretada - não haveria o fazer de conta.

Observação: a linguagem gerada é a de um quadro sobre como "as coisas eram” na época em que ocorreram. Há distanciamento e os papéis são de intermediários - os agentes que construirão a imagem do passado.

Guia: pastores encontraram evidências de que pessoas andam usando seu abrigo - sinais de cavalos, lixo. À distância, observam um encontro entre ladrões e um comerciante. Ficam com medo de interferir, mas foram vistos pelos ladrões. $\mathrm{Na}$ vila, suas mulheres esperam ansiosas, vão ao seu encontro e os descobrem amarrados e bastante machucados.

Observação: a linguagem gerada é a dos que contam - eles viram - eles estavam lá. É importante que a violência haja ocorrido no passado, e que a tensão do momento presente esteja concentrada na impossibilidade de revidar. É fundamental que os alunos não sejam solicitados a fazer de conta que estão lutando, porque isto seria inverossímil e, portanto, ridículo.

Autoridade: os participantes, como os pastores e suas mulheres, são conduzidos ao templo para fornecer detalhes sobre rumores de que haviam sido atacados após um roubo, e que um padre e um Levita deixaram de socorrer o homem que fora ferido, passando com indiferença pelo local. Os pastores e as mulheres são pressionados a mudar de opinião e admitir que estavam enganados. A cena estará centrada na força da autoridade e na pressão. A classe representará as autoridades, o professor será o pastor que estará representando todo o grupo de pastores. O contrário seria problemático, pois o professor ao assumir um personagem de autoridade corrupto estaria ensinando posturas e linguagem equivalentes.

Observação: a linguagem gerada é a do questionamento sobre o assunto - exigir esclarecimentos, definições, explicações, de tal maneira que o registro seja útil 
para as investigações.

Repórter: os pastores já se incomodaram o suficiente com este evento e com o samaritano e não querem mais problemas. Eles se sentem ameaçados pela atitude de seus interlocutores. Formas distintas de entrevistas podem ser exploradas: direcioná-la para agradar as autoridades e considerar "o caso encerrado"; para realizar uma reportagem sensacionalista e mostrar "um mundo cão"; para estabelecer a ordem, identificando os responsáveis.

Observação: a linguagem gerada é de dois tipos: diálogo, durante a entrevista, e forma escrita ou narrada para veicular a notícia.

Pesquisador: um hospital a ser inaugurado pretende utilizar a parábola "O bom samaritano" como símbolo para divulgar que: a) eles dão assistência a todos que precisam de ajuda; b) dar assistência requer recursos financeiros, lugar seguro e tempo integral; c) todos podem ser bons samaritanos - basta querer.

Observação: a linguagem gerada é a da busca de como este evento será visto à luz das questões mais amplas. O grupo deverá incluir a história na logomarca e na divulgação do hospital. É necessário considerar que: a) o hospital precisa de alguma forma mostrar que existe; b) o planejamento do apelo - a forma, o estilo, os meios; c) a autorização daqueles que planejam.

Crítico: uma empresa de marketing preparou um programa referente à campanha do hospital e despertou tanto interesse que está concorrendo a um prêmio jornalístico. O material está sendo examinado por críticos que darão seu parecer posteriormente.

Observação: a linguagem gerada é a de pessoas que analisam e interpretam o evento a fim de expressar sua opinião sobre o assunto. $\mathrm{O}$ professor deve considerar que: a) o programa deve ser percebido como se realmente existisse; b) deve haver evidências comuns disponíveis a todos os participantes; c) deve haver meios de examinar estas evidências; d) é necessário tempo para absorver as evidências; e) é necessário tempo para comentar o estilo, a forma e o conteúdo; f) é necessário um público convidado pelos críticos.

As perspectivas de enquadramento apresentadas acima vão requerer papéis e funções distintas por parte dos participantes. Em decorrência, estes usarão linguagem e atitudes de acordo com sua função e status. Ao propor "O bom samaritano" como pré-texto, Heathcote conduziu um processo de Drama estruturado através de episódios, e indicou a alternativa de alterar a perspectiva de enquadramento da situação e do grupo em cada episódio, ou em grande parte deles. Neste sentido, foi possível observar e vivenciar a parábola sob perspectivas distintas. Ao fazer isso, os participantes percebem as implicações das atitudes tomadas, ou não tomadas, e usam jogos de linguagem próprios de cada contexto.

\section{Episódios: decomposição e significação}

Heathcote conduz processos de Drama caracterizados como uma seqüência de episódios delimitados pelo mesmo pré-texto. Cada episódio significa - em - si, isto é, focaliza um aspecto do pré-texto que é apresentado e apreciado independente do que o antecedeu. Trata-se de um processo de decomposição - de uma peça, um 
texto, um problema ético, de paradoxos e metáforas de ordem pessoal ou social que já possui um percurso traçado na área da pedagogia do teatro.

Ao analisar as cenas Brechtianas, Barthes parte da estética de Diderot e sua identificação entre cena teatral e pintura: "a peça perfeita é uma sucessão de quadros, isto é, uma galeria, uma exposição: a cena oferece ao espectador tantos quadros reais, quantos momentos há na ação, favoráveis ao pintor” ${ }^{23}$. No teatro épico de Brecht (que procede por quadros sucessivos), diz Barthes,

[...] toda a carga significante e aprazível incide sobre cada cena, não sobre o conjunto; ao nível da peça, não há desenvolvimento, não há amadurecimento, há um sentido conceptual, certamente (até mesmo em cada quadro), mas não há um sentido final, são apenas recortes, cada um com suficiente força demonstrativa ${ }^{24}$.

Esta carga significante e aprazível que incide sobre cada cena foi considerada posteriormente por Lessing como instantes plenos. O teatro de Brecht e o cinema de Eisenstein, diz Barthes, são seqüências de instantes plenos. $\mathrm{O}$ cinema de Eisenstein inclui todas as ausências (lembranças, lições, promessas), que tornam a história simultaneamente inteligível e desejável. Em Brecht, é o gestus social que retoma a idéia do instante pleno. Este:

[...] é um gesto, ou um conjunto de gestos (mas nunca uma gesticulação) onde se pode ler toda uma situação social [...] nem todos os gestus são sociais: não há nada de social no gesto que faz um homem para espantar uma mosca; mas se esse mesmo homem, mal vestido, debate-se contra cães de guarda, esse gestus torna-se social $[\ldots]^{25}$.

Para Brecht o gesto social pode ser observado até mesmo na língua. Uma linguagem pode ser gestual, ele afirma, quando ela indica certas atitudes que o orador adota em relação aos outros. Assim como a linguagem, as atitudes são socialmente construídas, e determinam a forma com que percebemos o mundo. Desvendar estas atitudes, e perceber o que Wittgenstein considera como "o poder enganador da linguagem" é o desafio da educação contemporânea. Segundo o filósofo, as formas de falar não são elementos isolados e sim uma parte profundamente arraigada de nosso estilo de pensar e expressar, que nos mantém sob controle ${ }^{26}$. Ele esclarece que não podemos forçar o pensamento, mas para se chegar a uma atitude pensante é necessário que se produza um corte. Ao longo de seu trabalho, fez algumas observações sobre a maneira pela qual podemos chegar a observações esclarecedoras ao abordar um fenômeno (ou problema) por uma perspectiva diferente: memórias, descrições, chistes, metáforas e ironia. Acima de tudo, buscar clareza e compreensão através da linguagem.

O trabalho de Heathcote revela um método de ensino centrado em diferentes níveis de intervenção do professor nas formas de ver o mundo e interagir em grupos, em torno de conflitos e solução de conflitos. Ao propor formas distintas de enquadra-

\footnotetext{
${ }^{23}$ BARTHES, Roland. O óbvio e o obtuso. 4. ed. Rio de Janeiro: Nova Fronteira, 1990. p. 86.

24 BARTHES, 1990, p. 87.

${ }_{25}$ BARTHES, 1990, p. 88.

26 HEATON, John M. Wittgenstein y el psicoanálisis. Barcelona: Gedisa, 2004. p. 14.
} 
mento para um mesmo texto ou pré-texto, ela está mudando perspectivas e priorizando a linguagem como forma de intervir na ação do grupo e levá-lo a interagir entre si e em relação ao texto e contexto. Segundo Heathcote, Drama não é um recontar de histórias; ao alterar perspectiva e função na investigação de atitudes e ações, o sujeito começa a notar novos aspectos da situação sendo explorados e os conflitos se dissolvem com a compreensão decorrente do que se diz e se faz no novo contexto. A situação de investigar um problema no decorrer de distintos episódios permite, assim, compreender e dar nome às confusões de linguagem e pensamento, esclarecendo as relações que se encontram em estado de confusão.

As diferentes formas de focalizar e analisar uma narrativa desenvolvida através de episódios têm em comum a identificação e acentuação de um foco de atenção para tornar cada momento significante em si. Em termos estruturais, é possível ter uma história, e dividi-la em episódios, a fim de explorar diferentes perspectivas ou enfatizar detalhes (processo de segmentação), ou ter um episódio inicial que irá gerar situações ou questões para novos episódios que deverão ser conectados posteriormente para formar a narrativa (processo de composição).

A importância de se considerar as formas de estruturar a narrativa em Teatro/ Drama-Educação está associada ao fato de que o crescimento e reconhecimento desta área do fazer teatral passa pela necessidade de estabelecer similaridades e diferenças com fazeres afins, condição esta que delimitará seu espaço entre as artes contemporâneas. 


\section{REFERÊNCIAS}

BARTHES, Roland. O óbvio e o obtuso. 4. ed. Rio de Janeiro: Nova Fronteira, 1990.

BENJAMIN, Walter. Versuche über Brecht. Frankfurt: Sührkamp, 1981.

CABRAL, Beatriz. Signs of a post-modern, yet dialectic, practice. Research in Drama Education, Oxford, v. 1, n. 2, p. 215-220, 1996.

HEATON, John M. Wittgenstein y el psicoanálisis. Barcelona: Gedisa, 2004.

HORNBROOK, David. Education in drama. Londres: Falmer Press, 1991.

KOUDELA, Ingrid. Brecht: um jogo de aprendizagem. São Paulo: Perspectiva, 1991.

LACEY, Stephan; WOOLLAND, Brian. Drama in education and radical theatre practice. New Theatre Quarterly, Cambridge, v. 8, p. 4-15, 1992.

O’NEILL, Cecily. Dram worlds: a framework for process drama. Londres: Heinemann, 1995.

O'NEILL, Cecily. Ways of seeing: audience function in drama and theatre. 2D, n. 8, p. 1729, 1989.

ROBINSON, Ken. Exploring theatre and education. Londres: Heinemann, 1980.

STEINWEG, Reiner. Das lehrstuck. Stuttgart: Metzler, 1972. 284 p.

TAYLOR, Philip (Ed.) Pre-text and storydrama: the artistry of Cecily O'Neill and David Booth. Austrália: NADIE, 1995. 55 p. (Research monograph series, n. 1).

WRIGHT, Elizabeth. Post-modern Brecht. Londres: Routledge, 1984. 